\title{
ARQUIVOS
}

\section{A ORGANIZAÇÃO DE UM ARQUIVO LOCAL: UMA EXPERIENCIA.}

Um dos grandes problemas do historiador brasileiro é, sem dúvida, a falta de ordenação das nossas fontes primárias ou a sua destruição, por elementos que desconhecem o seix valor, e isso vem acontecendo desde os tempos coloniais. Yisando sanar esta situação de calamidade, já foram tomadas oficialmente algumas medidas no sentido de controlar e salvaguardar, em benefício da Nação, a documentação existente. A Constituição Federal já prevê a defesa pelos poderes públicos, do nosso patrimônio histórico e artístico (1). O Regimento do Arquivo Nacional, decreto $n . \circ 44.862$, de 21 de novembro de 1958 , no seu artigo $2^{\circ}$, I, determina que, ao Arquivo Nacional compete

"recolher, registrar, inventariar, classificar, catalogar, guardar e conservar os documentos escritos, cartográficos, fotocinematográficos e sonoros, provenientes dos órgãos integrantes dos Poderes da União, e das entidades privadas por êle instituída",

e no parágrafo IV, determina as mesmas medidas, com referência à documentação

"proveniente de entidades públicas não integrantes dos Poderes da União, ou de origem particular".

Mas, na realidade, um recolhimento sistemático não tem sido realizado. Assim, quer por falta de cumprimento das leis, por condições deficientes dos arquivos, ou por descuido, a documentação vem sendo destruída.

Uma questão paralela e igualmente importante, é selecionar aquilo que deve ser guardado, tendo em vista o historiador do futuro. No Brasil, vigora o critério de separação

(1). - "As obras, monumentos e documentos de valor histórico e artístico, bem como os monumentos naturais, as paisagens e os locais dotados de particular beleza ficam sob a proteção do poder público" (artigo 175, da Constituição Federal de 18 de setembro de 1946). 
da documentação dita histórica daquela considerada administrativa, critério êsse abandonado por tôdas as nações pioneiras nas questões de arquivos. A própria definiçãc de arquivo como

"tôda a acumulação de papéis e documentos de qualquer natureza, reunidos para servir de referência à atividade passada ou atual" (2),

já por si invalida e condena tal separação. Entretarıto, no Brasil, a documentação histórica tem sido dividida entrie os Arquivos, Museus e Secções de Manuscritos das Bibliotecas, pois a legislação federal não é bastante clara na discriminação das funções de cada uma dessas repartições, com relaç̃̃o ao recebimento e conservação de documentos.

O Arquivo Nacional reproduz bem a situação de pouco interêsse da União pela preservação de nossos documentos. O relatório do antigo Diretor do Arquivo Nacional, dr. José Honório Rodrigues (3) é altamente elucidador do provlema, pois trata-se de um dos melhores conhecedores das questões arquivísticas e históricas.

Com referência ao Estado de São Paulo, o problema da salvação e conservação da documentação ainda rão foi satisfatòriamente resolvido. Desde o século XVIII, existe um Arquivo Público em São Paulo, atualmente ligado à Secretaria da Educação do Estado de São Paulo e organizado em duas secções: Histórica e Administrativa (4). A Secção Histórica concentra manuscritos valiosos do período Colonial até o período republicano. Infelizmente, a partir de 1889, o Arquivo quase não tem recebido nova documentação. Enquanto esta secção se estagnou, a Secção Administrativa de outra parte, apresentou desenvolvimento regular. As razões são diversas, mas a principal é a falta de um planejamento para o futuro crescimento do Arquivo e daí vigorar no Arquivo Público do

(2). - Rodrigues (José Honório) - A pesquisa histórica no Brasil. Rio de Janeiro, Imprensa Nacional. 1952, pág. 197.

(3). - Rodrigues (José Honório). - A situação do Arquivo Naclonal. Rio de Janeiro, M. J. N. I., 1959.

(4). - Cf. Maria Regina da Cunha Rodrigues, o Departamento do Arquivo do Estado de São Paulo, in "Revista de História" n.* 50. 1962, págs. 475-494. 
Estado de São Paulo uma nítida separação da documentação dita histórica, da administração. O regulamento do Arquivo Público do Estado de São Paulo, decreto n. 29.922 de 18 de setembro de 1957 , no capítulo I, art. $3 .^{\circ}$, parágrafo I, determina que ao Arquivo do Estado compete:

"centralizar o acêrvo de todos os arquivos de processos administrativos findos, das diversas Secretarias de Estado condicionado o prazo desta centralização a prévio entendimento entre o Departamento do Arquivo do Estado e as autoridades responsáveis pelos vários arquivos". No parágrafo II determina "guardar e conservar os documentos históricos e todos os processos, documentos, papéis ou livros públicos ou particulares, de qualquer natureza, que possam aproveitar à história do Estado ou do Brasil" e ainda no parágrafo IV, "guardar e conservar os livros, documentos processos e papéis que tenham pertencido a repartições extintas".

Todavia, do ponto de vista prático, o processo para doação de documentação ao Arquivo (artigo 6.\%), não é feito de molde a estimular as doações, tais as dificuldades burocráticas nêle encontradas. E' de se lamentar, pois, novas doaçōes só poderiam enriquecer o acêrvo e facilitar a tarefa do pesquisador.

Quanto ao interior do Estado está êle abandonado à sua sorte, no tocante à documentação. Daí as notícias que freqüentemente recebemos sôbre a perda e destruição de preciosos manuscritos. A documentação oficial ficou na dependência dos prefeitos interioranos, que na sua maioria nõo se interessam por papéis antigos considerados "papéis velhos". A justificação apresentada é uma constante: falta de espaço. Mesmo na construção dos modernos paços municipais, o local reservado ao arquivo não é suficiente ou mesmo não é previsto, ou se reduz a algumas estantes. Há mesmo uma falta de compreensão generalizada sôbre o valor dos arquivos e de uma organização racional para a sua boa utilização. Infelizmente, não há uma ligação efetiva entre o Arquivo Público do Estado de São Paulo e o interior do Estado

O Município de Rio Claro, Estado de São Paulo, não foge à regra geral na questão de arquivos. Apesar de tor uma história recente, de pouco mais de um século, já perdeu Rio Claro a maior parte da documentação do período imperial. Considerando que, se nenhuma medida fôsse tomada, dentro em pouco não restaria mais nada dêsses documentos e que já cons- 
titui um problema o estudo de alguns aspectos da história local, resolvemos tentar sanar essa lacuna. Pensamos então em. concentrar tôda a documentação que ainda existe, num único local: Museu Histórico. Resolveríamos o problema da "falta de espaço" das repartições oficiais, a questão do destino a darà documentação particular, além da vantagem que essa centralização traria para a pesquisa. Assim, poderemos salvar o que. ainda resta e impedir a destruição futura, enquanto se espera: uma política nacional de salvação dos arquivos.

\section{* * $*$ \\ DA NECESSIDADE DE UM ARQUIVO L.OCAL.}

As medidas tomadas pelo govêrno com relação à centralização de documentos administrativos nas capitais, não tem: produzido até hóje os resultados que se poderiam esperar. $\mathrm{O}$ mesmo se poderá dizer também dos pequenos centros. Daí o. nosso projeto de criar um Arquivo Histórico local, que concentrasse tôda a espécie de documentação do Município, protegencio-a e possibilitando o seu acesso aos estudiosos. Seria uma medida efetiva de salvação física dos documentos à espera de. uma legislação aplicada à documentação dos pequenos centros. Contrariando as modernas normas arquivísticas que não separam arquivo histórico e administrativo, nós o adotainos como. uma solução local e provisória, para um problema local e imediato, sem pretensões de torná-la rígida e definitiva.

A idéia da formação de um arquivo municipal $€$ não regional foi resolvida em função da área a ser delimitada. A divisão geográfica não corresponde à divisão administrativa. A concentração de manuscritos em uma cidade, derttro de uma região, além do grave problema da área a ser cot taria inevitáveis ciúmes locais, além da dispersão de esforços. Depois, uma das modernas técnicas na formação de arquivos é não deslocar os manuscritos do lugar de origem.

O Município de Rio Claro, situado na "bôca do sertão" na época da expansão cafeeira, possui uma documentação falha pela perda e extravio de seus manuscritos, especialmente os do Império. Rio Claro apresenta uma riqueza de sugestões para futuras pesquisas históricas por ter sido a zona da primeira 
rentativa de utilização do braço livre, uma das primciras cidades de interior a ter imprensa, a segunda cidade do Brasil a ter iluminação elétrica, importante foco do movimento republicano e local de uma das primeiras concentrações de eucaliptos como solução para o reflorestamento. Quanto à imprensa, Rio Claro chegou a ter, em fins do século XIX e início do século XX cêrca de 70 periódicos, dos quais só existe uma coleção completa.

A formação de um arquivo local apresentava-se fois, como uma tarefa inadiável. Concentrar os papéis oficiais $\epsilon$ de particulares em um local com condições técnicas favoráveis e acessível aos estudiosos seria o primeiro passo. Por meio de campanhas nos jornais e especialmente por intermédio dos alunos da Faculdade de Filosofia, Ciências e Letras de Ric Claro, procuramos alertar a população para a importância da preservação de documentos. Como resultado, recebemos apreciável número de doações, tais como: cartas, convites, passaụortes, salvo condutos, escrituras, cartas patentes da Guarda Nacional, cadernos de receitas, de escrituração comercial e caseira, etc.

Resta ainda, entretanto, muito para fazer. A cidade de Rio Claro foi no passado importante centro rural. Infelizmente, não tivemos tempo suficiente para fazer um levantamento compelto dos possíveis arquivos particulares existentes nesse setor. Temos, todavia, uma amostra pre iosa sôbre a riqueza de tais arquivos com a valiosíssima doaçâo para o arquivo local da documentação da Fazenda Prates, a'ıtiga Santa Gerrtrudes.

\section{O ARQUIVO HISTÓRICO DE RIO CLARO.}

O acervo documental rioclarense, embora recerte, já está em situação crítica, pois a grande maioria dos manuscritos do período imperial se perdeu. O mesmo aconteceu cóm a documentação do antigo Cartório de Orfãos da cidade, cuja quase totalidade de manuscritos desapareceu, por ter sido o acervo dividido em 1846, entre a Prefeitura Municipal e o Cartório do 1. ${ }^{\circ}$ Ofício. Igual sorte tiveram os primeiros Livros do Tombo da Igreja Matriz, que não encontramos nem em Riı Claro, nem em Piracicaba ou Campinas.

Por ocasião do arrolamento das fontes primárias de Rio Claro, feita pela Cadeira de História, da Faculd:ule de Filo- 
sofia, Ciências e Letras de Rio Claro (5) conseguimos localizartôda a documentação oficial e particular, inclusive do núclea. alemão rioclarense.

A participação das autoridades municipais e dos particulares durante o arrolamento foi positiva. As autoridades municipais estão interessadas e tem prestigiado e auxiliado a iniciativa da formação do arquivo, cujo benefício parı a comunidade bem sabem avaliar. Quanto aos particulares a sua colaboração tem sido excelente e seu auxílio será fator educativo. Os elementos de penetração foram os alunos do Curso de Ciências Sociais e os estudiosos da história local. Assim, foi feita. a localização da documentação da zona urbana. Dividimos a cidade em zonas e cada aluno ficou incumbido ds pesquisarum trecho, casa por casa. O resultado foi ótimo no sentido Je um levantamento mais detalhado e quanto à colct? de material. Além disso, êsse trabalho teve um cunho educativo, pois. serviu para esclarecer o particular quanto à importîicia do documento escrito.

Depois de realizar o levantamento da situação documental de Rio Claro, tomamos as primeiras medidas preliminares para a organização do futuro arquivo. Como rrofessôra. de História da Faculdade de Filosofia, Ciências e Letras de Rio Claro, solicitamos ao Govêrno do Estado, por intermédio de seu Deputado Estadual, Sr. José Felício Castelar: a criação de um Museu Histórico na cidade. Assim, pelo decreto 40.445, de 23 de abril de 1962, publicado no Diário Oficicl de 24 dejulho de 1962, foi criado o Museu Histórico e Pedag j́gico "Amit-. dor Bueno da Veiga". A legislação dos Museus Históricos e Pedagógicos do Estado de São Paulo, Ato 199, de 20 de abril de 1957, determina no capítulo I, artigo $3 .^{\circ}$, que

"os Museus constarão de objetos históricos e artís-. ticos, biblioteca e arquivo". No capitulo II, artigo 11, determina que "os Museus à medida que se desenvolverem. deverão compor-se de: a) Secção de documentação histórica que compreenderá biblioteca, filatelia, mapoteca, estampas; b) Arquivo, documentação fotográfica, publicações e intercâmbio cultural". No capítulo III, artigo 12, determina "classificar os documentos históricos e manter atualizado o arquivo".

Daí justifica-se a instalação do arquivo no prédio do Museu histórico local.

(5). - Castro (Jeanne B. de) e Witter (J. S.). - Arrolamento das fontes his-. tóricas de Rio Claro, in "Revista de História", n.o \$8. 1964, págs. 427-453. 
Para a instalação da sede do Museu conseguimú; que fôsse aprovada a Lei Municipal n. 835, de 26 de dezembro de 1962, pelo qual foi cedido ao Museu o sobradão da Earonesa de Dourados, por 20 anos prorrogáveis de $10 \mathrm{em} 10$ anos, enquanto o Museu estiver em funcionamento.

Resolvida a primeira parte da criação oficial de um arquivo e de sua futura sede, restava o problema principal da concentração da documentação oficial e particular nesse local, que deveria ser cedida por doação ou custória. Com referência aos documentos oficiais da Prefeitura Municipal, o primeiro contacto que tivemos fôra por ocasião do arrolamento das fontes primárias de Rio Claro. Encontramos boa vontade por parte das autoridades municipais, especialmente a valiosa cooperação e orientação do Sr. Humberto Mônaco, Diretor Administrativo da Prefeitura Municipal. Greças ao Sr. Mônaco, pudemos localizar a documentação municipal, que corria o risco de se perder - devido a ausência de cuidados - segundo as modernas técnicas de preservação de documentos. Assim, dos dias 24 a 27 estivemos nos porões da antiga sede da Prefeitura Municipal retirando a documcntação do período imperial (1837-1889) e do período republicano (18891930) até o fim da República velha. Os documentos achavamse todos misturados quanto ao assunto, data e procedência. Não foram recolhidos ainda os documentos mais recentes por serem de utilidade para a Prefeitura para fins de certidões e relatórios. O número atual de documentos avulsos é de cêrca de 10.000 e dos livros 1.294. Foram os mesmos transportados provisòriamente para a Faculdade, para os primeiros trabalhos de limpeza e desinfecção, pois, além do môfo e poeira, alguns livros estavam bichados. Muitos documentos estavam presos por grampos enferrujados, alguns rasgados $e$ outros com fôlhas misturadas. Não possuindo a Bibliotera da Faculdade um fôrno para desinfecção, usamos nos livsos uma solução cuja fórmula nos foi fornecida pela bibliotecária da $\mathrm{Fa}-$ cudade e que é a seguinte: álcool a $60^{\circ}$, oxianureto de $\mathrm{HG}$, creosoto, essência de alfazema, essência de cravo. Nos documentos avulsos, limpos um a um, além da solução acima, usamos neocid em pó e por último polvilhamos tudo com BHC.

Terminada esta tarefa iniciamos o trabalho de organização e classificação, seguindo a orientação de relatórios antigos dos primeiros prefeitos. Obedecemos a terminologia e classificação usada na Prefeitura Municipal, uma vez que quando encontramos os documentos, estavam êles misturados. Os 
mesmos foram colocados em pastas de cartolina. segundo assunto e ordem cronológica.

Quanto aos documentos avulsos estamos fichando cada um segundo o modêlo usado na Secção Histórica do Arquivo Público do Estado de São Paulo e cujo modêlo é o seguinte:

De quem:

loc. e data:

A quem:

Assunto:

Observação:

P. Doc. (pasta n.)

No anverso está anotada a procedência do dociumento e a data de recebimento. Os documentos.avulsos estão guardados em pastas de cartolina, sendo azul para o império, verde paraa república e laranja para documentos de particul sres. Estão guardados em fichários de aço, estando os documentus nos gavetões e as fichas nas gavetas pequenas, o que fac:lita a procura e o manuseio dos manuscritos. Cada pasta agrupa documentos de um mesmo assunto e dispostos por crdem cronológica.

Quanto aos livros, será colocado em cada umä f tiquêta e depois guardados em estantes de aço de fácil mantseio. Para cada volume foi feita uma ficha individual com as seguintes indicações: título da obra, data, indicação do númerc de fôlhas numeradas, rubricadas e utilizadas, o resumo do assunto e as medidas do livro. No anverso da ficha estão marcarlas a procedência e a data de entrada. Um resumo muito Jeialhado é desnecessário, pois o historiador quer apenas uma indicação para a procura.

Nessa tarefa a Cadeira de História contou com a colaboração voluntária de um grupo de 11 alunos do Curso de Ciências Sociais e que foram os seguintes: Ana Maria R. Jordão, Elisa Granito, Elizabeth V. Dória, Isalise Mamede, José Roberto Höfling, Lélia Gardenal, Lígia Maria Leite, Maria Helena Altenfelder Silva, Maria Sílvia Beozzo, Sílvia Maria Pezzotti, Sônia Maria Calligaris, que fizeram o trabalho de limpeza, desinfecção e triagem preliminar. As alunas Elizabeth V. Dória, Maria Helena Altenfelder Silva, Maria Sílvia Beozzo realizaram o trabalho posterior de nova classificação e da feitura das fichas.

Entusiasta dos problemas municipalistas, o culto e esclarecido vereador, Sr. Sílvio Januário Pezzotti, apresentcu a nos- 
tódia, do arquivo e documentação histórica do Munlcípio de Rio Claro.

Parágrafo único - A entrega será feita contra recibo, fícando a documentação em poder do Museu, que se obrigará conserva-los da melhor forma possivel.

Artígo 2.0 - A seleçāo do arquivo e da documentação será feita pela direção do Museu, ou por elementos pela mesma credenciados e abrangerá o periodo compreendido entre a fundação de Rio Claro e o ano de 1930 .

Parágrafo único - Excluem-se da documentação a ser entregue os livros de Ata, que permanecerão nos arquivos desta Edilidade.

Artigo 3.0 - Esta Resolução entrará em vigor na data de sua publicação, revogadas as disposiçōes em contrário.

Rio Claro, 6 de dezembro de 1963.

Antônio Maria Marrote: Presidente

Publicado no Diário de Rio Claro, em 12 de dezembro de 1063.

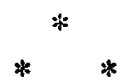

LEI N. ${ }^{\circ} 885$ DE 13 DE DEZEMBRO DE 1963.

Eu, Oreste Armando Giovanni, Prefeito Municipal de Rio Claro, Estado de São Paulo, usando das atribuiçōes que me são conferidas por lei, faço saber que a Câmara Municipal de Rio Claro aprova e eu promulgo a seguinte:

LEI N.O 885.

(Autoriza a cessão ao Museu Histórico e Pedagógico "Amador Bueno da Veiga" em custódia, do arquivo e documentação histórica do Município de Rio Claro).

Artigo 1.0 - Fica a Prefeitura Municipal de Rio Claro autorizada a estabelecer convênios com o Museu Histórico e Pedagógico, "Amador Bueno da Veiga" de Rio Claro, visando à entrega, ao mesmo, do arquivo e documentação históricos do Município de Rio Claro.

Artigo 2.0 - A entrega do arquivo e da documentação referida no art. 1. ${ }^{\circ}$, será feita em custódia, permanecendo dito arquivo e documentaçāo em poder do Museu Histórico Pedagógico "Amador Buenos da Veiga", para efeitos de pesquisas e estudos da história do Município de Rio Claro.

Artigo $30^{\circ}$ - A seleção do arquivo e da documentação do Município de Rio Claro, em poder da Prefeitura Municipal será feita pela direção do Museu Histórico Pedagóglco "Amador Bueno da Veiga", ou por elementos pela mesma credenciados e abrangerá o período entre a fundação de Rio Claro e o ano de 1930.

Artigo $4 .^{\circ}$ - A presente lei entrará em vigor na data de sua publicação, revogadas as disposiçōes em contrário.

Rio Claro, 13 de dezembro de 1963.

Oreste Armando Giovanni.

Prefeito Municipal.

Publicada na Prefeitura Municipal de Rio Claro, na mesma data supra.

Humberto Mônaco - Diretor Geral do Departamento de Administração.

Publicada na cidade de Rio Claro, aos 19 de dezembro de 1963. 
so pedido, um projeto de lei junto a Câmara Municipal de Rio Claro, no sentido de que a documentação oficial administrativa municipal, ficasse sob a guarda do Museu. Assim, pela Lei n. 885, de 13 de dezembro de 1963 foi autorizada a

"cessão ao Museu Histórico e Pedagógico "Amador Bueno da Veiga" em custódia, do arquivo e documentação histórica do Município de Rio Claro".

Tôda a documentação da Prefeitura Municipal foi entregue ao Museu depois de ter sido lavrada em ata o atr da doação. Quanto à Câmara Municipal, pela Resoluçãu n. 77, de 6 de dezembro de.1963, foi autorizado a

"ceder ao Museu Histórico e Pedagógico "Amador Bueno da Veiga", a documentação histórica referente ao $\mathrm{Mu}$ nicípio de Rio Claro".

O período abrangido pela doação vai da fundeção de Rio Claro até $1930(6)$.

Em abril de 1964, como resultado efetivo dos trabalhos de organização do arquivo, resolveu a Prefeitura Muricipal designar o estudioso da história local, Sr. Oscar Penteado, para vistoriar e inventariar o que ainda ficara na Prefeitura Munici$\mathrm{pal}$. Os documentos e livros que sobraram, foram entregues ao Museu, em obediência à lei municipal já em vigor. Fci enviada à Prefeitura Municipal um inventário simples de tôda a documentação em poder do Museu.

Possui atualmente o arquivo, além dos "fundus" de documentos oficiais, um fundo de documentos particulares dos mais variados, como o da documentação da Fazenda Prates. Para cada um dêsses "fundos" será usado o mesmo procedimento acima explicado, tendo em vista a procedência dus mesmos .

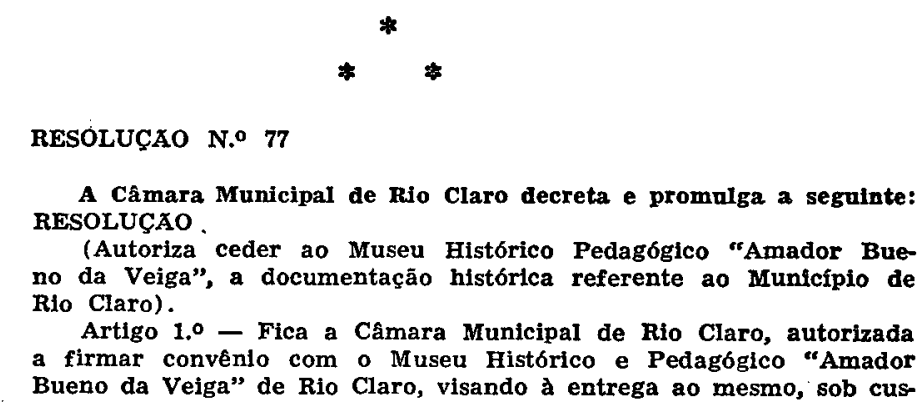

(6). - Vide a legislação. 


\section{CONCLUSÃO.}

Temos a convicção, fruto de uma experiência de trabalho e pesquisa, de que a organização de arquivos em cada cidade é. fator de primordial importância, como base para estudos não só históricos, como de economia, sociologia, administração, educação, geografia, etc. Trata-se de tarefa urgente, cujo adiamento não se justifica e que deverá se desenvolver em tôdas as cidades.

Este trabalho, entretanto, deve ser dirigido por persoas que tenham conhecimento de História, uma vez que nos faltam especialistas em arquivos. E' tarefa delicada e de resfonsabilidade, pois dela depende a vida dos documentos. Sem um especialista, só o historiador, ou professor de História, poderá se incumbir de tão importante missão. O que urge é organizar arquivos em número cada vez maior, a fim de salvar os documentos que ainda nos restam.

No I Simpósio dos Professôres Universitários de História, realizado em 1962, em Marília, foi sugerido que a dir eção dos arquivos ficasse a cargo dos professôres de História de cada região, especialmente onde houvesse Faculdade df: Filosofia (7).

A Associação dos Professôres Universitários de História, secção regional de São Paulo, se propôs a fazer o levantamento estadual das fontes primárias de São Paulo e pesquisas documentais (8). Acreditando na importância do plano, iniciamos em Rio Claro o arrolamento das fontes primárias (9), a organização de um arquivo histórico e o inventáric detalhado da documentação administrativa municipal de Rio Claro e que pretendemos apresentar no III Simpósio dos Professôres Universitários de História.

O nosso trabalho, iniciado em 1963, não poderia ter sido concluído se não fôsse o auxílio integral da população de Rio Claro que teve, como elemento de penetração dos mais eficientes, o entusiasmo e apôio dos alunos da Faculdade de Filosiofia, Ciências e Letras de Rio Claro.

JEANNE BERRANCE DE CASTRO

Professôra da Cadeira de História, da Faculdade de Filosofia, Ciências e Letras de Rio Glaro.

\footnotetext{
(7). - Anais do I Simpósio de Professóres de História de Ensino Superior. Marilia, 1962, pág. 298.

(8). - Cf. Maria Regina da Cunha Rodrigues, As fontes primárias para a História no Estado de Săo Paụlo, in "Revista de História", n.o 53. 1963, págs. 165-176.

(9). - Castro (J. B.) e Witter (J. S.), op. cit., pág. 4.
} 